\title{
In-situ Observation of Ordering Transformations in $\mathrm{\theta}-\mathrm{Al}_{2} \mathrm{O}_{3}$
}

\author{
Libor Kovarik $^{1}$, Konstantin Khivantsev ${ }^{2}$, Mark Bowden ${ }^{2}$ and Janos Szanyi ${ }^{2}$ \\ ${ }^{1}$ Pacific Northwest National Laboratory, Richland, Washington, United States, ${ }^{2}$ Pacific Northwest \\ National Laboratory, United States
}

Metastable polymorphs of $\mathrm{Al}_{2} \mathrm{O}_{3}$ (transition aluminas) are heavily used in catalytic applications due to their advantageous thermal and surface properties [1]. In the group of transition aluminas derived by thermal decomposition of boehmite, there are three known polymorphs denoted as $\gamma-\mathrm{Al}_{2} \mathrm{O}_{3}, \delta-\mathrm{Al}_{2} \mathrm{O}_{3}$ and $\theta$ $\mathrm{Al}_{2} \mathrm{O}_{3}$. The polymorph of $\theta-\mathrm{Al}_{2} \mathrm{O}_{3}$ is the most stable transition alumina, forming only at the highest temperatures $\left(950-1050^{\circ} \mathrm{C}\right)$ by transformation from $\gamma-\mathrm{Al}_{2} \mathrm{O}_{3}$ and $\theta-\mathrm{Al}_{2} \mathrm{O}_{3}$ [2-4]. Because of the highly defective and disordered nature of the earlier forming polymorphs, the mechanism of $\theta-\mathrm{Al}_{2} \mathrm{O}_{3}$ formation remains poorly understood. In the current study we present in-situ TEM heating studies aimed at revealing the mechanism of $\theta-\mathrm{Al}_{2} \mathrm{O}_{3}$ formation.

The microstructural observations were performed with a probe corrected FEI Titan 80-300. The image collection was done in Scanning Transmission Electron Microscopy (STEM) mode using a HAADF detector at $300 \mathrm{kV}$. Selected samples were heated in-situ using a double tilt Aduro Protochips heating holder. The heating experiments were performed at $1000-1100^{\circ} \mathrm{C}$, and the observations were performed at room temperature after each successive heat treatment in order to minimize beam damage. The observations allowed us to track the evolution of microstructure for individual particles at the atomic level.

For boehmite derived samples, the decomposition is traditionally considered to proceed in the sequence of $\gamma-\mathrm{Al}_{2} \mathrm{O}_{3} \rightarrow \delta-\mathrm{Al}_{2} \mathrm{O}_{3} \rightarrow \theta-\mathrm{Al}_{2} \mathrm{O}_{3}$. In our presentation, it will be shown that the decomposition of $\gamma-\mathrm{Al}_{2} \mathrm{O}_{3}$ to $\theta-\mathrm{Al}_{2} \mathrm{O}_{3}$ can proceed directly through the formation of a highly disordered precursor state that is denoted as $\theta^{\prime}-\mathrm{Al}_{2} \mathrm{O}_{3}$. The formation of such a disordered state is accompanied by the formation of $\delta-\mathrm{Al}_{2} \mathrm{O}_{3}$, which is often the main component of the evolving microstructure. An example from $1000{ }^{\circ} \mathrm{C}$ heat-treated microstructure accommodating both phases is shown in Figure $1 . \theta^{\prime}-\mathrm{Al}_{2} \mathrm{O}_{3}$ can be recognized from a series of non-periodically distributed high intensity features (fully occupied octahedral sites), which can be rationalized as $\delta$-like defects embedded within the crystal of $\theta-\mathrm{Al}_{2} \mathrm{O}_{3}$ considering $\beta-\mathrm{Ga}_{2} \mathrm{O}_{3}$ structural type.

Upon further heating at $1000{ }^{\circ} \mathrm{C}$, the microstructure of $\theta^{\prime}-\mathrm{Al}_{2} \mathrm{O}_{3}$ undergoes ordering before it transforms to $\theta-\mathrm{Al}_{2} \mathrm{O}_{3}$. An example of an ordering transformation after additional 20 -minute heat treatment at $1000^{\circ} \mathrm{C}$ is shown in Figure 2. Multiple periodicities can be identified within the more ordered segments. The interpretation of such a structural state can be provided as a linear combination of monoclinic crystals with $\mathrm{A} 2 / \mathrm{n}$ space group, which are related to $\delta-\mathrm{Al}_{2} \mathrm{O}_{3}$ and $\theta-\mathrm{Al}_{2} \mathrm{O}_{3}$ (considering the structure of $\beta-\mathrm{Ga}_{2} \mathrm{O}_{3}$ ). The final transformation to $\theta-\mathrm{Al}_{2} \mathrm{O}_{3}$ involves a reduction of number of $\delta$-like defects, but even after prolonged high temperature treatment, as found through a combination of ex-situ and in-situ heating experiments, the defects are not eliminated. The residual amount is expected to be entropically stabilized. As a part of this work, we will discuss the role of $\theta^{\prime}-\mathrm{Al}_{2} \mathrm{O}_{3}$ in the formation of $\theta-\mathrm{Al}_{2} \mathrm{O}_{3}$, and show how the new observations can help to rationalize the often-observed slow kinetics of $\delta-\mathrm{Al}_{2} \mathrm{O}_{3}$ to $\theta-\mathrm{Al}_{2} \mathrm{O}_{3}$ transformations [5]. 

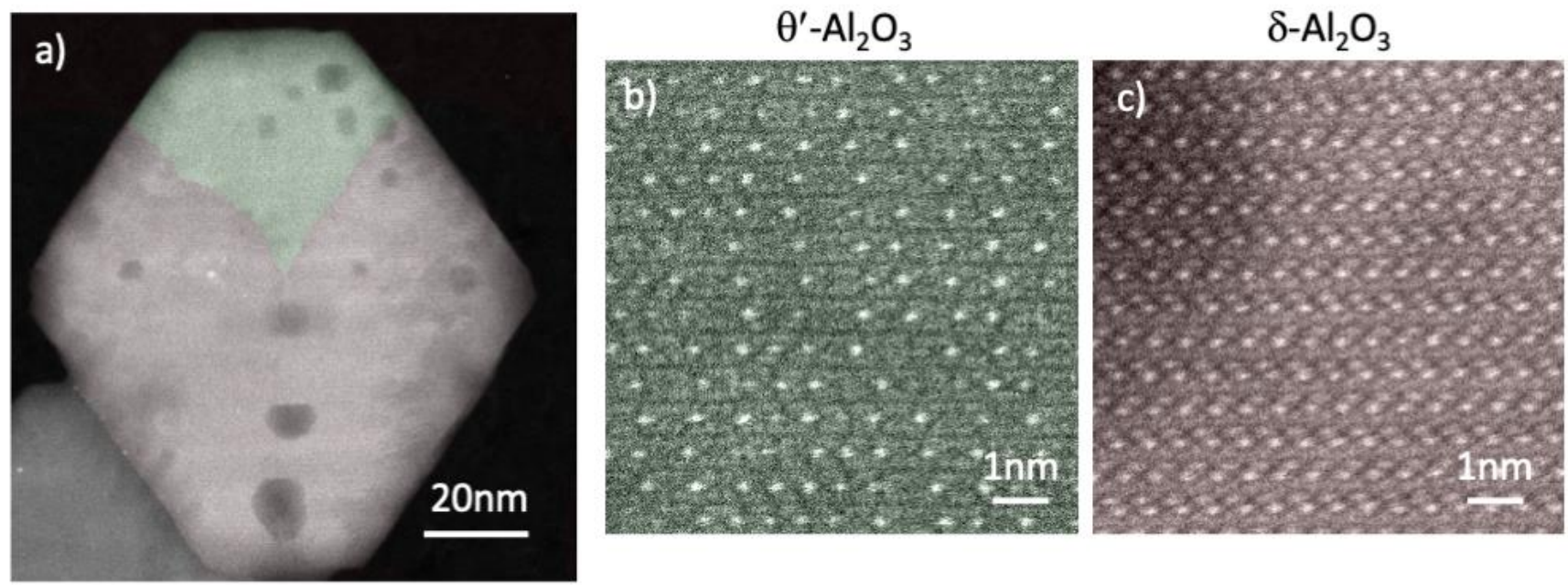

Figure 1. (a) Particle of transition $\mathrm{Al} 2 \mathrm{O} 3$ studied during in-situ heating at $1000{ }^{\circ} \mathrm{C}$. The microstructure evolves to (b) disordered precursor state of $\theta-\mathrm{Al} 2 \mathrm{O} 3$ and (c) planar intergrowth structure of $\delta$-Al2O 3 .
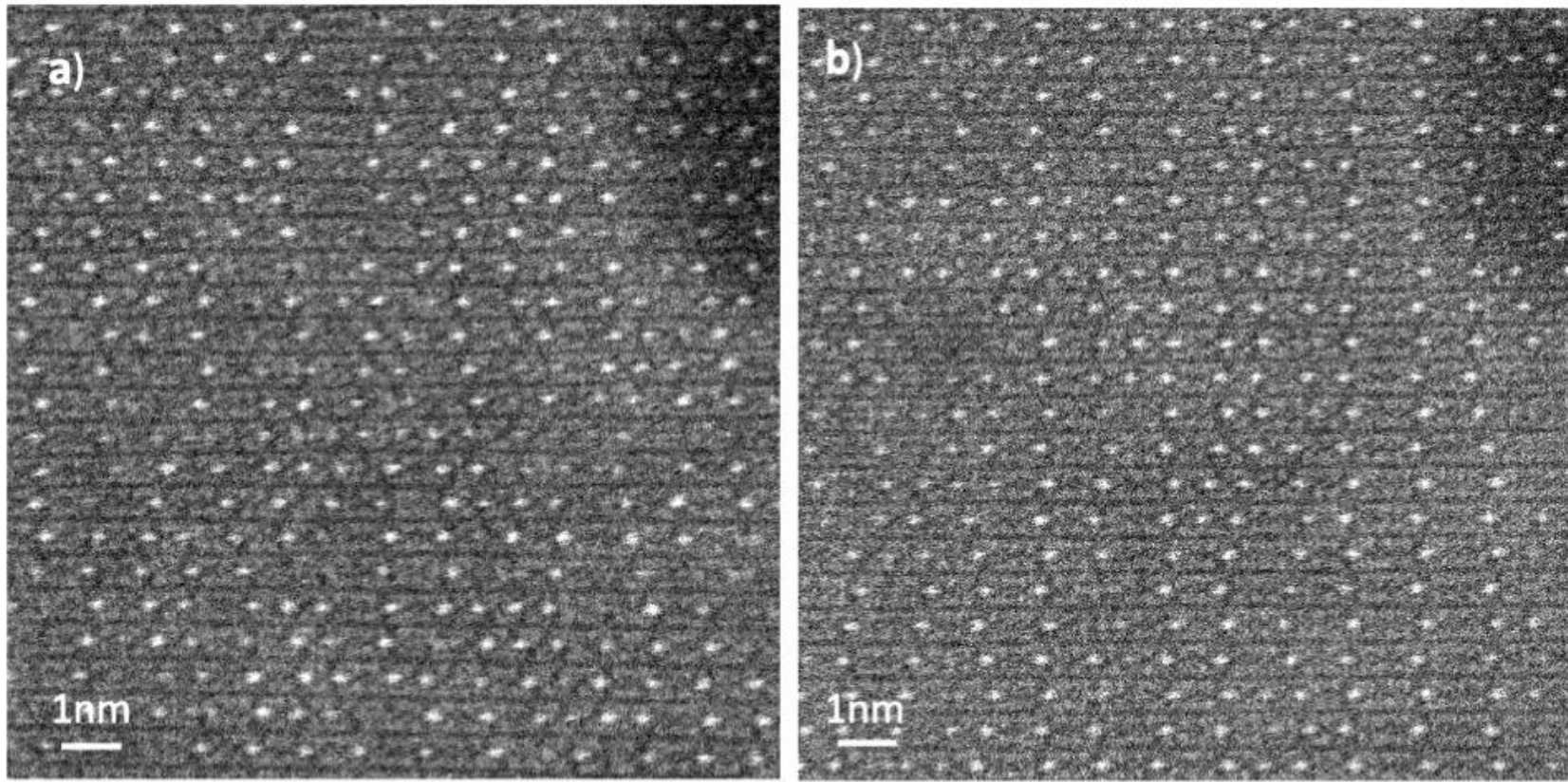

Figure 2. Evolution of $\theta^{\prime}$-Al2O3 during in-situ heating: (a) $\theta^{\prime}$-Al2O3 heated to $1000{ }^{\circ} \mathrm{C}$, (b) ordering within $\theta^{\prime}$ $\mathrm{Al} 2 \mathrm{O} 3$ after additional heating for $20 \mathrm{~min}$ at $1000^{\circ} \mathrm{C}$.

\section{References}

[1] Busca, G. (2013), Catalysis Today, 1-12.

[2] Kovarik, L., Bowden, M., Shi, D., Washton, N. M., Andersen, A., Hu, J. Z., et al.,. Chemistry of Materials, 27(20), 7042-7049. (2015)

[3] Kovarik, L., Bowden, M., \& Szanyi, J. (2021). Journal of Catalysis, 393, 357-368.

[4] Kovarik, L., Bowden, M., Andersen, A., Jaegers, N. R., Washton, N., \& Szanyi, J. (2020). Angewandte Chemie International Edition, 59(48), 21719-21727.

[5] This research was performed in the Environmental Molecular Sciences Laboratory (EMSL), a national scientific user facility sponsored by DOE's Office of Biological and Environmental Research and located at PNNL. It was supported by the U.S. DOE, Office of Basic Energy Sciences, Division of Chemical Sciences, Biosciences and Geosciences. 